
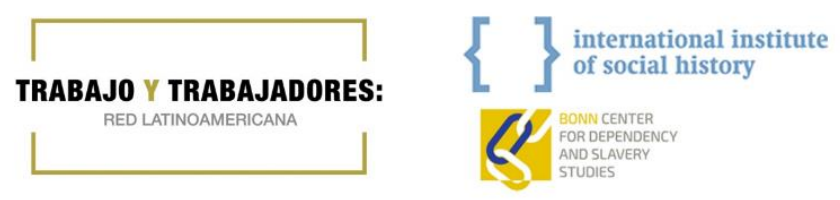

\title{
CRÍTICA DE LIBROS
}

Juan Marchena, Manuel Chust, Mariano Schlez, El debate permanente. Modos de producción y revolución en América Latina (Santiago de Chile: Ariadna, 2020), 576 pp.

Hay retornos poco esperados que, sin embargo, se perciben como inevitables en el momento que se producen. En la alta coyuntura global que experimentaron los diferentes marxismos a partir de los años 1960, el concepto de "modos de producción" tuvo recorrido particular. En varias regiones del mundo se convirtió, durante algunos años de la década de 1970, en la "estrella del día". Desde el punto de vista actual, llaman la atención las diferentes lecturas que tuvo esta categoría marxiana (que, dicho sea de paso, tampoco tiene un significado estable en los escritos del propio Marx). El espectro va desde interpretaciones filosóficas con alto grado de abstracción hasta lecturas antropológicas en las que se utilizaba como categoría heurística. Uno de los centros de este debate global -y el caso menos conocido hoy en la academia predominantemente anglófona- fue América Latina. Es allí donde también tuvo lugar la apropiación más historicista del concepto que lograba integrar, en un raro momento de equilibrio intelectual en la historia de los marxismos, perspectivas teóricas-conceptuales con hallazgos empíricos-ideográficos. Como cúspide del debate funge la famosa compilación de tapa marrón que llevaba el sencillo título de Modos de producción en América Latina, publicado en 1973, como volumen número 40 de los "Cuadernos de Pasado y Presente”, con textos de Carlos S. Assadourian, Ciro F.S. Cardoso, Horacio Ciafardini, Juan C. Garavaglia y Ernesto Laclau. Es un ícono de la historia intelectual latinoamericana: aunque un ícono poco evocado en los debates actuales de las historiografías del subcontinente.

Es por lo tanto motivo de celebración que un equipo de historiadores e historiadoras, de diferentes partes de América Latina y España, se hayan propuesto la tarea de reabrir y revisitar este debate sobre los modos de producción vinculándolo, a la vez, con otro tema perenne de la historia 
política y social de América Latina: las revoluciones. El resultado es una voluminosa compilación de casi 600 páginas que surgió de un congreso celebrado en 2018 en la Universidad Pablo de Olavide en Sevilla (declaración de transparencia: el autor de estas líneas participó como invitado en este congreso) y se publica ahora como un libro de acceso abierto.

Como no sería posible ni prudente darle la debida apreciación a todas las contribuciones, me enfocaré en la parte del libro que trata de los modos de producción y en dos dimensiones que, a mi parecer, ofrecen algunos puntos de debate: primero, el intento presente, en varias contribuciones, de una historización reflexiva de los mismos debates sobre los modos de producción; segundo, en qué medida el libro y su afán de reavivar el debate sobre los modos de producción dialoga con las recientes discusiones en la historia global del trabajo.

No es posible revisitar un debate de tanta trascendencia intelectual y política sin hacer un esfuerzo consciente por entender la historia del debate mismo, sus trayectorias, actores, condiciones y apuestas. Es sobre todo en las contribuciones de los co-compiladores Mariano Schlez y Manuel Chust donde se ofrece tal apreciación crítica de los debates sobre modos de producción y las revoluciones respectivamente.

Es impreciso, insiste Schlez, plantear el histórico debate latinoamericano sobre los modos de producción como una variante o una mera reacción crítica a las interpretaciones historiográficas de las teorías de la dependencia que surgieron en la década de 1960. Es innegable que hay una estrecha interrelación entre estos debates y Schlez tiene toda la razón cuando afirma que la preocupación por los modos de producción tiene una trayectoria más larga y ramificada que se remonta, por lo menos, a los años 1920. Fue entonces cuando, bajo el signo de la presencia comunista y sus disidencias en el pensamiento crítico del subcontinente, se estableció aquel específico lenguaje que buscaba determinar el carácter socioeconómico de las sociedades latinoamericanas en épocas coloniales y poscoloniales para trazar, a partir de allí, las conclusiones que marcaran el horizonte del cambio político a emprender. Schlez reconstruye en forma detallada y precisa la sinuosa trayectoria del debate, haciendo particular hincapié en las apuestas políticas pro o contrarrevolucionarias, donde se implicaban atributos como "feudal" o "capitalista". Incluye muchos detalles que solo se conocieron recientemente como la relación cercana entre Jan Bazant, el posteriormente reconocido historiador social de la historia colonial mexicana, y el León Trotsky del exilio mexicano. Como suele ser habitual en las ciencias interpretativas, la 
fuerza de argumento de Schlez, en cierto modo, también representa una limitación: una y otra vez la trayectoria converge en el lente "trotskiano” con la contienda entre "revolución permanente vs. teoría de etapas” como un hilo rojo que atraviesa y envuelve todo. Esto ciertamente es un marco explicativo desde lo político que resulta poderoso (y que tendrá las simpatías de muchas lectoras y lectores, entre ellos el autor de estas líneas), pero tiende a dejar en las sombras algunas curvas de lo sinuoso de aquella trayectoria intelectual. Esto se revela, por ejemplo, en la medida en que atributos como "feudal" o "capitalista" eran fluidamente intercambiables entre varios intelectuales lanzando posiciones que no correspondían a su afiliación política. Con todo, Schlez finaliza su argumento afirmando que el mérito del debate sobre modos de producción (que varias veces se había caracterizado también como una reacción filo-comunista frente a los desafíos de la dependencia) fue precisamente el de superar el dualismo entre las posiciones "feudales" y “capitalistas”. Y lo más llamativo, como demuestra Schlez, es cómo el concepto de modos de producción permitió a los historiadores a principios de los años 1970 imaginar la superposición y coexistencia interrelacionada de diferentes formas de organización social durante la época colonial.

Estas miradas auto-historizantes se encuentran en numerosas contribuciones como las de Tristán Platt sobre modos de producción en los Andes, Carlos Bojórquez-Urzaiz, Adrián Mercado y Gabriela Martínez junto con Eduardo Azcuy sobre los casos maya, de la provincia de Tucumán y del Virreinato del Río de la Plata respectivamente; también Stella Granat contribuye a esto con un análisis de la caracterización socioeconómica de América Latina hecha por León Trotsky en su exilio mexicano.

Manuel Chust ofrece, en un ensayo corto, varias pautas para repensar las historiografías de las revoluciones tal y como se han desarrollado desde la Segunda Guerra Mundial. Repasando algunas intervenciones teóricas e historiográficas clave (como las de Hannah Arendt, Robert Palmer o Jacques Godechot) señala la manera en que una visión tan liberal como noratlántica iba definiendo las "buenas revoluciones" como procesos más bien institucionales e intraélite, es decir sin la reñida intervención popular, y como limitadas al Atlántico Norte, es decir omitiendo las complicadas contiendas revolucionarias en otras partes, sobre todo en la región que después se conocería como América Latina.

Ahora bien, ¿cómo dialogan las contribuciones de este libro con las discusiones en la historia del trabajo? Puesto de otra forma: ¿puede ser útil para la historia del trabajo reapropiarse del concepto de modos de producción 
y los correspondientes debates? Como se ha mencionado, ya desde Marx la determinación sobre qué es precisamente un modo de producción era relativamente cambiante. Intuitivamente parece obvio que denota un conjunto de relaciones que incluyen el trabajo, la propiedad, las tecnologías y las instituciones (una lista que, por cierto, amerita ser complementada), y las diferentes lecturas se diferencian justamente por el énfasis. Pero si hay un solo elemento que se sobreimpone ciertamente sería el primero, es decir la organización social del trabajo. Varias de las contribuciones muestran claramente que ahí reside el mayor peso explicativo, sea en la discusión del trabajo indígena en varios contextos, la producción agrícola para la exportación o la transición abolicionista en casos como el de Haití. En este sentido, cualquier estudio inspirado en el concepto de modos de producción dialoga en forma directa con las inquietudes de la reciente historia del trabajo que justamente ha buscado ensanchar su noción del "trabajo" y "trabajador" para incluir, más allá del clásico proletariado asalariado, todas las formas en que se explotaba el trabajo.

Repasando las contribuciones del libro y comparándolo con la historia del trabajo se hacen visibles dos virtudes y dos debilidades del mismo. Entre las virtudes está, primero, la gran sensibilidad para imaginar el trabajo no solamente desde el punto de vista del trabajo mismo sino desde su regulación y realmente su "creación" jurídica y política-institucional, sobre todo frente a las diferentes poblaciones indígenas en varios contextos coloniales (Manuel B. Chacón sobre formas de imponer tributos frente a los indígenas en la Costa Rica colonial, Adrián Mercado sobre derecho indiano en el Tucumán del siglo XVII y María del Mar Muñoz sobre el Fondo Piadoso de las Californias). Segundo, las contribuciones que reconstruyen el trabajo desde las formas de propiedad y la historia del capital (José Luis Caño sobre el capital minero en Guanajuato, Luis Miguel Pardo sobre la producción tabacalera en el Caribe colombiano decimonónico y Pablo Volkind sobre la formación de un mercado de trabajo agrario en la Argentina a partir de 1880). Más allá del gastado atributo "feudal", la fortaleza del concepto de modos de producción es la atención que presta a aquellas constelaciones históricas en las que lo económico era inmediatamente político. Aunque se refiera siempre a cómo se organizaba socialmente el trabajo, el concepto permite deslizarse analíticamente hacia otras esferas de lo social: una demanda que se escucha a menudo en las discusiones metodológicas de la historia del trabajo.

Hay, en cambio, dos importantes lagunas, tanto en el debate histórico como en esta primera reevaluación actual. La más importante es lo que podríamos 
llamar la "trampa de la producción" que tiende a omitir las vastas actividades humanas (en muchos contextos predominantemente femeninos) que son reproductivas y de subsistencia inmediata. Ciertamente, el concepto de modos de producción puede ser desarrollado mucho más ampliamente en esta dimensión fundamental puesto que su integración permite una completa explicación de las condiciones sociales de la “producción”. Segundo, mientras el debate histórico sobre los modos de producción permitía imaginar la coexistencia simultánea de diferentes modos de producción, no ha desarrollado lo suficiente la pregunta de la interrelación (en un contexto regional pero también a través de largas distancias) entre estos diferentes modos, es decir darle un fundamento más sistemático y empírico a lo que en la época se llamaba “articulación”. Es cierto que autores clásicos como Eric Wolf se han distinguido, justamente, por ofrecer un análisis de la interacción de los diferentes modos de producción, pero las contribuciones al presente libro retoman el afán regionalista del histórico debate (que, no se debe olvidar, también fue una crítica al continentalismo simplificador de muchos de los análisis dependentistas). Queda pendiente la tarea de analizar estas interrelaciones con mayor profundidad, utilizando, tal como se dice en el lenguaje de la historia del trabajo, las múltiples interacciones entre trabajo libre y no-libre.

El título del libro tiene varias apuestas claras. Más allá de la política, señala que la discusión sobre modos de producción tiene una larga trayectoria, una continua relevancia, y por lo tanto, un futuro. $\mathrm{Su}$ aparato conceptual indudablemente tiene un alto poder explicativo para quienes se interesan por el tema del trabajo y su historia. A la vez, es claro que hay que amplificar el concepto para integrar las actividades reproductivas ( $\mathrm{y}$, posiblemente, otras esferas más de lo social), para pensar más sobre las interrelaciones de diferentes modos locales, y finalmente, para considerar las interrelaciones de larga distancia. "Modos de producción" - no se debe olvidar- es una de las pocas propuestas conceptuales que permiten reconciliar lo que se ha presentado, en el debate decolonial o en la discusión sobre los límites de una nueva historia global, como irreconciliable: el análisis de especificidades locales en toda su particularidad junto con las interrelaciones suprarregionales y sus dinámicas abarcadoras.

DAVID MAYER

Universidad de Viena, Austria david.mayer@iisg.nl 